Powerful outflows from newborn stars can energize space well beyond the main boundaries of a galaxy.

Sanchayeeta Borthakur at Johns Hopkins University in Baltimore, Maryland, and her colleagues used the Hubble Space Telescope to probe 20 nearby galaxies. Each galaxy had gone through a burst of star formation within the past few hundred million years.

The authors found that winds flowing from the newborn stars ionize gas particles some 200 kiloparsecs from the galactic centres. This is the first observation of such long-distance changes.

The outflows may modify galactic material in ways that suppress future star growth.

Astrophys. J. 768, 18 (2013)

ANIMAL BEHAVIOUR

\section{Fish match human} search strategy

A small tropical fish seems to scan its surroundings in a similar way to humans.

Archerfish (Toxotes spp.) shoot down their prey by spitting jets of water more than 1 metre into the air (pictured). Ingo Rischawy and Stefan Schuster at the University of Bayreuth in Germany trained archerfish to pick out stationary targets amid a distracting background and compared fish performance with that of people throwing tennis balls at a target. Although humans responded faster than the fish, response times for both increased linearly with the number of distracting background objects,

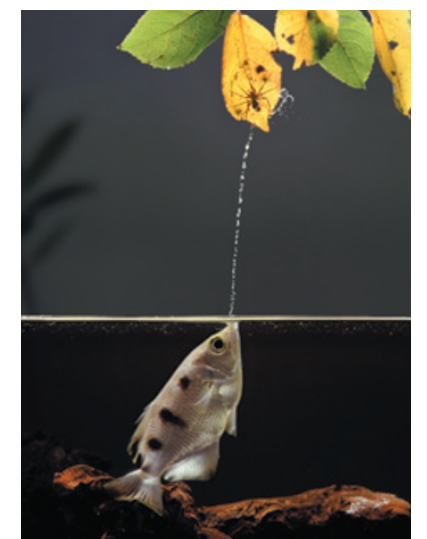

implying that the fish and humans use comparable search strategies.

Humans might share mechanisms for efficient visual search with animals that have much simpler brains, the authors say.

J. Exp. Biol. http://dx.doi. org/10.1242/jeb.087734 (2013)

\section{AGRICULTURAL ECOLOGY}

\section{Pollen powers honeybee genes}

Bees could be dying because they lack a nutrient found in honey.

The western honeybee (Apis mellifera) adds billions of dollars to the global economy by pollinating crops, but a mysterious 'colony collapse disorder' has killed off many hives. Agricultural pesticides, overcrowding, frequent transport and bee parasites have all been blamed.

Work by May Berenbaum and her colleagues at the University of Illinois at Urbana-Champaign suggests another contributing factor: honey substitutes, which are often fed to bees by commercial beekeepers. The researchers used liquid chromatography to identify compounds in honey that activate the genes known to be upregulated by the foodstuff, then analysed gene expression in bees that were fed different diets. Those fed $p$-coumaric acid, a compound found in pollen, expressed more detoxification genes than bees given plain sugar syrup. Bees fed the pollen compound also produced higher levels of genes for antimicrobial peptides.

Proc. Natl Acad. Sci. USA

http://dx.doi.org/10.1073/

pnas.1303884110 (2013)

\section{ROBOTICS}

\section{Tiny, winged machines}

Insect-sized robots can mimic the hovering and darting of flies.

COMMUNITY CHOICE

\title{
Mechanism for Alzheimer's delay
}

\section{HIGHLY READ \\ on www.cell.com in April}

Studies suggest that symptoms of Alzheimer's disease can be delayed if people keep their brains active, and researchers have now uncovered a potential underlying mechanism.

Dennis Selkoe, Shaomin Li and their colleagues at Harvard Medical School in Boston, Massachusetts, enhanced the environment of mice by frequently changing their toys. Synaptic plasticity - experience-dependent changes in connectivity between neurons that are associated with learning and memory - increased in mice living in novelty-rich cages for several weeks. The increase came, in part, from activation of $\beta_{2}$-adrenergic receptors.

The researchers then applied amyloid- $\beta$ protein, which is known to accumulate in the brains of patients with Alzheimer's disease, to brains from mice that had either been kept in an enriched environment or been given drugs that activate $\beta_{2}$-adrenergic receptors. Both conditions prevented the synaptic dysfunction that the protein normally causes.

Neuron 77, 929-941 (2013)

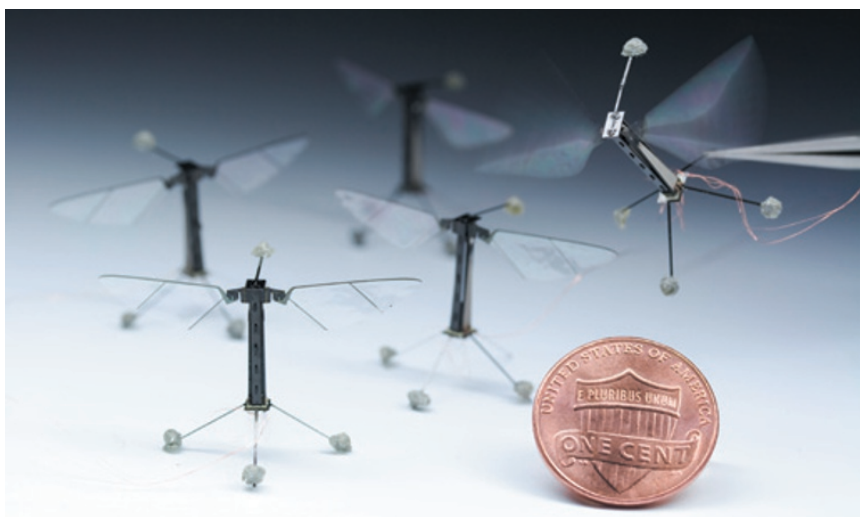

Flies have long been admired for their aerial agility, but technical limitations in miniaturization have hindered attempts to replicate this in similarsized robots. Kevin Ma and his colleagues at Harvard University in Cambridge, Massachusetts, have invented a specialized laser-manufacturing process that allowed them to create tiny composite structures, including mechanical wings and flight muscles. The researchers used the components to build 80 -milligram robotic flies with flapping frequency, wing stroke and energy use similar to that of real flies.

The mechanical flies (pictured) were capable of controlled flight manoeuvres and hovering in place. The work could open the door to additional innovations in miniaturized machines. Science 340, 603-607 (2013)

\section{NATURE.COM}

For the latest research published by Naturevisit:

www.nature,com/latestresearch 